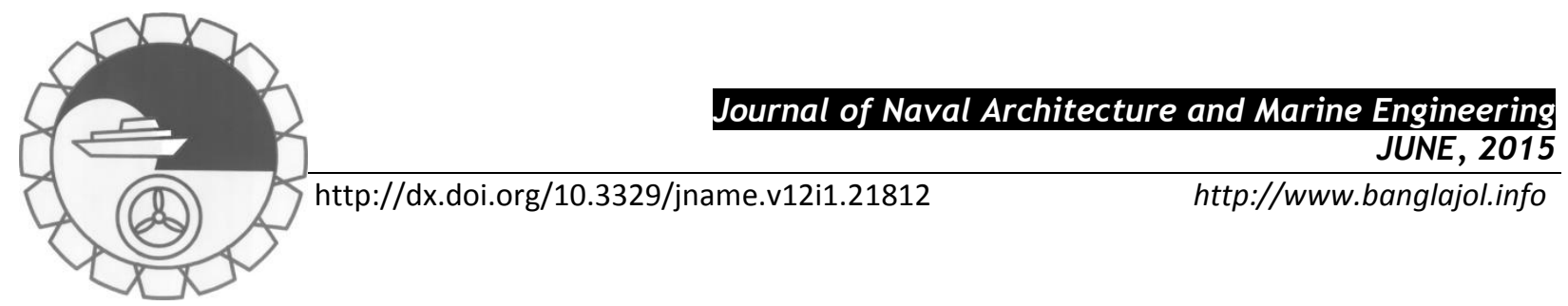

\title{
PREDICTION OF UNSTEADY MIXED CONVECTION OVER CIRCULAR CYLINDER IN THE PRESENCE OF NANOFLUID- A COMPARATIVE STUDY OF ANN AND GEP
}

\author{
Prasenjit Dey*, Abhijit Sarkar, Ajoy Kumar Das
}

Mechanical Engineering Department, National Institute of Technology Agartala, India

*Corresponding Author: prasenjitmit1@gmail.com

\begin{abstract}
:
Heat transfer due to forced convection of copper water based nanofluid in the presence of buoyancy has been predicted by the Artificial Neural network (ANN) and Gene Expression Programming $(G E P)$. The present nanofluid is formed by mixing copper nano particles in water and the volume fractions are considered here are $0 \%$ to $15 \%$ and the Reynolds number (Re) are varying from 80 to 180. The adding and opposing buoyancy affect is done by introducing Richardson number (Ri) as 1 and -1 respectively. The back propagation algorithm is used to train the network. The present ANN and GEP models are trained by the input and output data which have been obtained from the numerical simulation, performed in finite volume based Computational Fluid Dynamics (CFD) commercial software FLUENT. The numerical simulation based results are compared with the back propagation based ANN and GEP results. It is found that the mixed convection heat transfer of water based nanofluid can be predicted correctly by both the ANN and GEP but; GEP is found more efficient. It is also observed that the back propagation ANN and GEP both can predict the heat transfer characteristics of nanofluid very quickly compared to a standard CFD method.
\end{abstract}

Keywords: Mixed convection, circular cylinder, nanofluid, neural network, gene expression etc.

\section{Introduction}

Over the last many years, the flow and heat transfer around slender cylindrical bluff bodies has been the focus of intense research, mainly having the engineering importance on structural design, flow induced vibration, heat exchanger tube bundle, chimney stacks, cooling towers, etc. The major portion of these studies have been carried out for the flow past a circular cylinder, sharp edged square and triangular cylinder. Studies illustrate that the wake structure is agitated and the hydrodynamic fluxes propagate when the wake is strictly dominated by thermal buoyancy. Such kind of buoyancy possibly is introduced in the flow field by heating or cooling the cylinder surface that debased the condition of mixed convective consequence in the flow domain. In available studies, there are number of studies based on theoretical, experimental and numerical data on the flow and heat transfer around the circular cylinders over a wide range of Reynolds numbers, Prandtl numbers (Pr), power law fluids etc. (Chakraborty et al., 2004, Chhabra et al., 2004, Golani and Dhiman, 2004, Mahír and Altaç, 2008, Park et al., 1998, Posdziech and Grundmann, 2007, Shi et al., 2004, Tritton, 1959, Rahman et al., 2007). Golani and Dhiman (2004) has studied Fluid flow and heat transfer across a circular cylinder in the unsteady flow regime for $\operatorname{Re} 50$ to 180 at $\operatorname{Pr}=0.7$ by using CFD commercial software FLUENT. Mahir and Altac (2008) has investigated the unsteady laminar convective heat transfer from isothermal cylinders of tandem arrangement in the range of the Reynolds numbers of 100 and 200 and for centre-to centre distance ratio of 2, 3, 4, 5, 7 and 10 . Posdziech and Grundmann (2007) performed two-dimensional (2-D) numerical simulations of the flow around the cylinder for $\operatorname{Re}=5$ to 250 by using the spectral element method. They have shown that the unsteady drag variation was smaller compared to the steady case and the lift coefficient strongly increased with Reynolds number. Shi et al. (2004) investigated the effect of temperature dependent viscosity and density of air on the fluid flow and heat transfer from a heated cylinder for the range. It is observed that thermal conductivity of nanofluid is higher than that of the base fluids when the nanoparticles are mixed with a small amount (Eastman et al., 2001, Xuan and Li, 2000). The application of nanofluid in convection for different industrial purpose is introduced in preceding studies (Buongiorno, 2006, Kakaç and Pramuanjaroenkij, 2009). Recently, application of nanofluid on enhancement of heat transfer has studied (Daungthongsuk and Wongwises, 2007, Trisaksri and Wongwises, 2007). Mixed convection around a heated circular cylinder placed inside a vented square cavity has been studied for different diameter of the cylinder and different Ri in steady flow regime (Rahman et al., 2009). 
Various numerical and experimental studies of heat transfer characteristics by utilizing nanofluids has been studied and concluded in the literature (Khanafer et al., 2003, Tiwari and Das, 2007). Khanafer et al. (2003) investigated the heat transfer performance of nanofluids in a differentially heated enclosure and concluded that there is an enhancement in heat transfer rate due to the mixing of nanoparticles in the base fluid. The authors of the present paper (Dey and Das, 2014) also studied the natural convection heat transfer of a heated square cylinder placed inside a square enclosure by varying volume fraction of nanofluid and the Rayleigh Number (Ra). Most recently, (Sarkar et al., 2012), a study of the mixed convection of nanofluid under aiding and opposing buoyancy effect has been completed. They have taken volume fraction up to $25 \%$ and varying Ri as 1 and -1 . And the same authors (Sarkar et al., 2011) also studied the mixed convection over a circular cylinder at high Prandtl number; varying 0.7 to 100 . Mixed convection heat transfer of nanofluid in steady state condition in a lid driven cavity having some combination of heaters and coolers (HACs) inside is examined numerically (Garoosi et al., 2015) and found that at low Ri, heat transfer rate is directly related to number of heaters and coolers but at higher Ri, the heat transfer rate is not changing considerably. Another numerical solution of mixed convection of nanofluid in a square enclosure has been studied recently (Chen et al., 2014). A numerical study of mixed convection heat transfer of nanofluid around a heated circular cylinder placed inside a backward facing step channel has been accompanied (Selimefendigil and Öztop, 2015) and found that heat transfer rate is directly proportional to Re and volume fraction.

Although, all the heat transfer studies are based on experimentally or numerically and by using working fluid as air, water or nanofluid; but over the last few years, prediction of different characteristics of heat transfer and aerodynamic behavior is becoming an area of research in various engineering applications due to its less time consuming method. There are various techniques are used in production; between them Artificial Neural Network (ANN) is one of the most utilizing method. Recently, (Santra et al., 2009) the prediction of heat transfer in the presence of nanofluid using ANN has been studied and found that ANN can be used to predict heat transfer characteristics more efficiently and rapidly. Where, Gene Expression Programming (GEP) is an another algorithm having the advantages of both Genetic Algorithm (GA) and Genetic Programming (GP) to evaluate more complex function to present an expression of the relation between input and output (Ferreira, 2001). GEP is more efficient to predict the output as compared with ANN; is discussed recently (Martí et al., 2013).

By considering the foregoing studies, it is altogether okay to conclude that there is no prior study has been conducted on prediction of nanofluid based mixed convection over a circular cylinder. Therefore, in the present study, the prediction of unsteady mixed convection by utilizing nanofluid is studied by back propagation ANN and GEP. The Reynolds number is varied in the range of 80 to 180 , Ri is varying as 1 and -1 and solid volume fraction as 0 to $15 \%$. The input parameters are partly similar to Sarkar et al (2012). This present study aims to fill the gap in literature.

\section{Geometrical Configuration and Mathematical Formulation}

The system of interest here is to predict the mixed convection heat transfer characteristics around a circular cylinder in a channel at the symmetric horizontal line, schematically shown in Fig. 1. The circular cylinder of diameter ' $\mathrm{D}$ ' with constant wall temperature ' $\mathrm{T}_{\mathrm{w}}$ ' is held in a channel exposed to an upstream unsteady laminar flow of $\mathrm{x}$-velocity, ' $\mathrm{U}_{\infty}$ ' (free stream velocity) and temperature, ' $\mathrm{T}_{\infty}$ '. The objective is to perform on an infinitely long channel; but, the computational domain has to be limited. The distance of the upstream and the downstream boundaries from the center of the cylinder are $\mathrm{L}_{\mathrm{u}}=10 \mathrm{D}$ and $\mathrm{L}_{\mathrm{d}}=40 \mathrm{D}$. The distance between the upper and lower side-walls, $\mathrm{H}$, is specified according the blockage ratio $(\mathrm{D} / \mathrm{H}=0.05)$. The free-slip boundary condition is associated with the side-walls.

\subsection{Governing Equations}

The dimensionless governing equations for the two dimensional, laminar, incompressible nanofluid flow and heat transfer with constant thermo-physical properties and negligible dissipation effect can be expressed in the following forms: 
Continuity Equation:

$\frac{\partial u}{\partial x}+\frac{\partial v}{\partial y}=0$

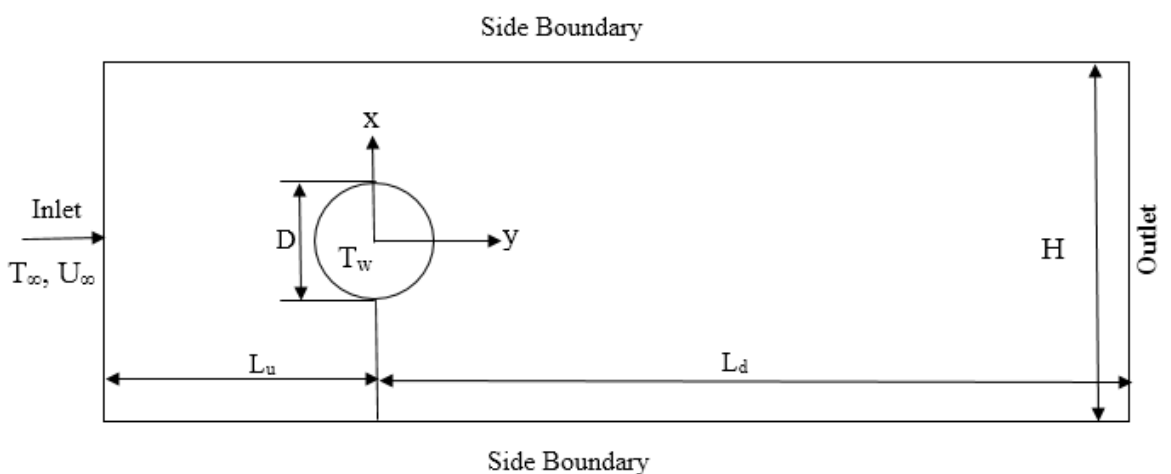

Fig. 1: A schematic diagram of the problem description

x-Momentum Equation:

$\frac{\partial u}{\partial t}+u \frac{\partial u}{\partial x}+v \frac{\partial u}{\partial y}=-\frac{\rho_{f}}{\rho_{n f}} \frac{\partial p}{\partial x}+\frac{\mu_{n f}}{v_{f} \rho_{n f}} \frac{1}{\operatorname{Re}}\left(\frac{\partial^{2} u}{\partial x^{2}}+\frac{\partial^{2} u}{\partial y^{2}}\right)$

y-Momentum Equation:

$\frac{\partial v}{\partial t}+u \frac{\partial v}{\partial x}+v \frac{\partial v}{\partial y}=-\frac{\rho_{f}}{\rho_{n f}} \frac{\partial p}{\partial y}+\frac{\mu_{n f}}{v_{f} \rho_{n f}} \frac{1}{\operatorname{Re}}\left(\frac{\partial^{2} v}{\partial x^{2}}+\frac{\partial^{2} v}{\partial y^{2}}\right)+\frac{\rho_{p} \beta_{p} \phi+\rho_{f} \beta_{f}(1-\phi)}{\rho_{n f} \beta_{f}} \operatorname{Ri}(\theta)$

Energy Equation:

$\frac{\partial \theta}{\partial t}+u \frac{\partial \theta}{\partial x}+v \frac{\partial \theta}{\partial y}=\frac{\alpha_{n f}}{\alpha_{f}} \frac{1}{\operatorname{RePr}}\left(\frac{\partial^{2} \theta}{\partial x^{2}}+\frac{\partial^{2} \theta}{\partial y^{2}}\right)$

where $\mathrm{u}, \mathrm{v}$ are the dimensionless velocity components along $\mathrm{x}$ and $\mathrm{y}$ directions of a Cartesian coordinate system respectively, $\mathrm{p}$ is the dimensionless pressure, $\operatorname{Re}\left(=\frac{\rho_{f} U_{\infty} D}{\mu_{f}}\right)$ is the Reynolds number based on the cylinder dimension, $\theta$ is the dimensionless temperature, $\operatorname{Pr}\left(=\frac{\mu_{f} C_{P f}}{k_{f}}\right)$ is the Prandtl number and $t$ is the dimensionless time. The fluid properties are described by the density $\rho$, dynamic viscosity $\mu$, thermal diffusivity $\alpha$ and thermal conductivity $\mathrm{k}$. The dimensionless variables are expressed as:

$u=\frac{\bar{u}}{U_{\infty}}, v=\frac{\bar{v}}{U_{\infty}}, x=\frac{\bar{x}}{D}, y=\frac{\bar{y}}{D}, \theta=\frac{T-T_{\infty}}{T_{w}-T_{\infty}}, t=\frac{U_{\infty} \bar{t}}{D}$

Where $\bar{u}$ and $\bar{v}$ are the velocity components in the $\bar{x}$ and $\bar{y}$ directions respectively, $\mathrm{T}$ is the temperature.

\subsection{Thermophysical properties of nano-fluid}

The different thermophysical properties of nano-fluid are defined as follows (Yacob et al., 2011):

$\mu_{n f}=\frac{\mu_{f}}{(1-\phi)^{2.5}}$ 
Where, $\phi$ is the nanoparticle volume fraction and is given as:

$$
\begin{aligned}
& \phi=\frac{\text { Volume of nanoparticles }}{\text { total volume of solution }} \\
& \rho_{n f}=(1-\phi) \rho_{f}+\phi \rho_{p} \\
& C_{p n f}=\frac{(1-\phi)\left(\rho C_{p}\right)_{f}+\phi\left(\rho C_{p}\right)_{p}}{\rho_{n f}} \\
& \frac{k_{n f}}{k_{f}}=\frac{\left(k_{p}+2 k_{f}\right)-2 \phi\left(k_{f}-k_{p}\right)}{\left(k_{p}+2 k_{f}\right)+\phi\left(k_{f}-k_{p}\right)}
\end{aligned}
$$

The thermophysical properties of fluid and nanoparticles at room temperature are given in Table 1 (Abu-Nada and Oztop, 2009).

Table.1: Thermophysical properties of nanofluid

\begin{tabular}{|c|c|c|c|c|}
\hline Fluid/ Nanoparticle & \multicolumn{4}{|c|}{ Thermophysical properties } \\
\cline { 2 - 5 } & $\rho\left(\mathrm{Kg} / \mathrm{m}^{3}\right)$ & $\mathrm{Cp}(\mathrm{J} / \mathrm{Kg} \mathrm{K})$ & $\mathrm{K}(\mathrm{W} / \mathrm{mK})$ & $\mu(\mathrm{Kg} / \mathrm{ms})$ \\
\hline Water & 997.1 & 4179 & 0.613 & 0.001 \\
\hline $\mathrm{Cu}$ & 8933 & 385 & 400 & - \\
\hline
\end{tabular}

\subsection{Boundary conditions}

The physical boundary condition for the above discussed problem configuration are written as follows:

- The left wall of the computational domain is designed as the inlet. The "velocity inlet" boundary condition is assigned at the inlet boundary with free stream velocity, $\mathrm{U}_{\infty}$, temperature $T_{\infty}$ and Neumann boundary condition for pressure is used $\left(\frac{\partial p}{\partial x}=0\right)$.

- The usual no-slip boundary condition is assigned for flow at the surface of the cylinder, i.e. $u=0$; $v=0$ with constant wall temperature of $\theta=1$ and normal gradient condition for pressure $(\nabla p . n=0$, where $n$ is the unit normal $)$.

- Free-slip boundary condition is assigned at the upper and lower surface of the computational domain, i.e. $\frac{\partial u}{\partial y}=0 ; \mathrm{v}=0 ; \theta=0$.

- The extreme right surface of the computational domain is assigned as an outlet. The "pressure outlet" boundary condition is employed at the exit boundary with a fully developed flow situation $\left(\frac{\partial u}{\partial x}=0, \frac{\partial v}{\partial x}=0, \frac{\partial \theta}{\partial x}=0\right)$ of Dirichlet type Pressure boundary condition $(\mathrm{p}=0)$. 
The heat transfer characteristic between the cylinder and the surrounding fluid is calculated by the Nusselt number. The local Nusselt number based on the cylinder dimension is given by:

$N u=\frac{h D}{k_{f}}=-\left(\frac{k_{n f}}{k_{f}}\right) \frac{\partial \theta}{\partial n}$

Where, $\mathrm{h}$ is the local heat transfer coefficient. Surface average heat transfer is obtained by integrating the local Nusselt number along the cylinder face.

\section{CFD Model}

\subsection{Grid structure and grid independence study}

The grid structure of the computational domain used in the present investigation is shown in Fig. 2. It is observed from the Fig. 2, that the non-uniform structured and non-structured grid assembly for the whole computational domain is assigned. Grids are generated by using the grid generation package GAMBIT. The expanded view of the section of the computational domain that is having the cylinder is shown in Fig. 2(b).

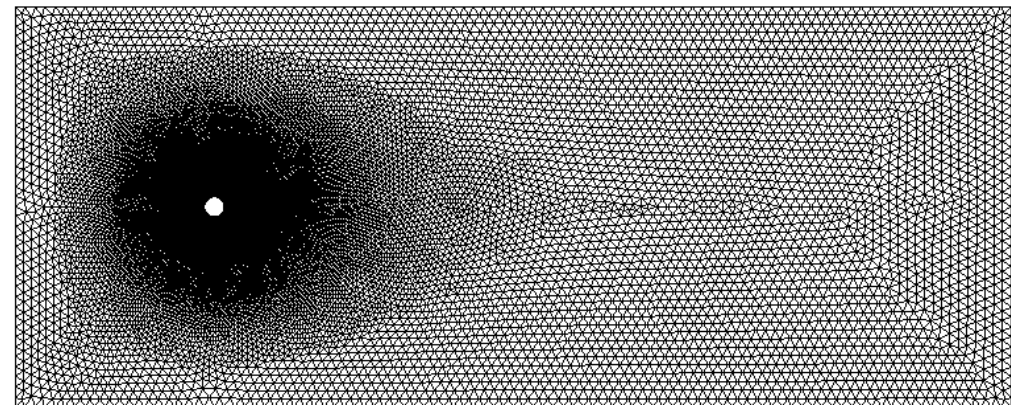

(a)

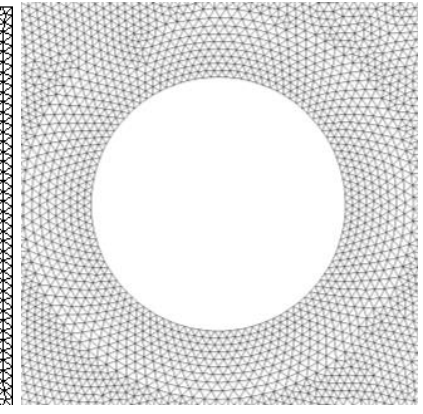

(b)

Fig. 2: (a) Grid Distribution of the computational domain (b) Zoomed view of the grid distribution of the cylinder.

The whole computational domain grid sizes are selected inadequate of the blockage ratio. The surface of the cylinder and the area nearer to it has the finer mesh to adequately capture the wake wall interactions in both direction and the grids becoming coarser non-uniformly towards the boundary wall. The smallest grid size of $0.07 \mathrm{D}$ of triangular element is incorporated with the surface of the cylinder and the grid size for the remaining surfaces is increasing linearly to $0.5 \mathrm{D}$ from the cylinder surface to the boundary.

In this study, three different mesh sizes (Grid1-15000, Grid2-25000 and Grid3-40000) are adopted in order to check the mesh independence. A detailed grid independence study has been performed and results are obtained for the average Nusselt number at $\phi=0.0$ and $\mathrm{Ri}=1$ but there is no considerable changes between Grid 2 and Grid3 (the results are shown in Table.2). Thus, a grid size 25000 is found to meet the requirements of the both grid independence and computation time limit.

Table 2: Study of effect of grid size for grid independence test

\begin{tabular}{|c|c|c|}
\hline \multirow{2}{*}{ No. of cells } & Re-100 & Re-180 \\
\cline { 2 - 3 } & $\mathrm{Nu}_{\text {avg }}$ & $\mathrm{Nu}_{\text {avg }}$ \\
\hline 15000 & 10.13792 & 15.79207 \\
\hline 25000 & 10.29234 & 16.08154 \\
\hline 40000 & 10.35409 & 16.15391 \\
\hline
\end{tabular}




\subsection{Numerical details}

In the present investigation, the numerical simulation is performed by using the finite volume based commercial CFD solver FLUENT 6.3 (Fluent, 2006). FLUENT is used to solve the governing equations which are the partial differential equations, using the control volume based technique in a collocated grid system. The solver used in the present work is pressure-based implicit method. Semi-Implicit Method for Pressure-Linked Equation (SIMPLE) is selected for the pressure-velocity coupling scheme. The pressure term is discretized under the scheme of STANDARD whereas the convective terms are discretized by second order upwind scheme. The unsteady laminar viscous model is used for the low Reynolds number consideration. The convergence criteria for the continuity and velocity are set to $10^{-5}$.

\section{Artificial Neural Network Model}

Artificial neural network (ANN) is a computational structure inspired by a biological neural system. An ANN consists of very simple and highly interconnected units called neurons. The neurons are connected to each other by links in which individual weights are passed and over which signals can pass. Each neuron receives multiple inputs from other neurons in proportion to their connection weights and generates a single output, which may be propagated to several other neurons (Sreekanth et al., 1999).

There are abundant distinct ways of implementation of a single artificial neuron. The general mathematical formulation of a single artificial neuron could be signified as:

$$
y(z)=f\left(\sum_{i=0}^{j} w_{i} z_{i}+b\right)
$$

Where, $\mathrm{z}$ is a neuron with $\mathrm{j}$ input $\left(\mathrm{z}_{0}\right.$ to $\left.\mathrm{z}_{\mathrm{n}}\right)$ and one output $\mathrm{y}(\mathrm{z})$ and where $\left(\mathrm{w}_{\mathrm{i}}\right)$ are weights determining how much the inputs should be weighted with b denoting the bias (Kurtulus, 2009). ' $f$ ' is an activation function that weights how powerful the output should be from the neuron, based on the sum of the inputs and expressed as:

$$
f(x)=\frac{1}{1+e^{-x}}
$$

The basic feedforward network performs a nonlinear transformation of input values in order to approximate the output values. For the present ANN model, three layers are used, namely one input layer, one hidden layer and one output layer. Connections in these kinds of network only go forward from one layer to the next where all the neurons in each layer are connected to all the neurons in the next layer. The designed neural network structure 3-5-1 (3 neurons in input layer, 5 neurons in hidden layer and 1 neuron in output layer) of the present study is shown in Fig. 3.

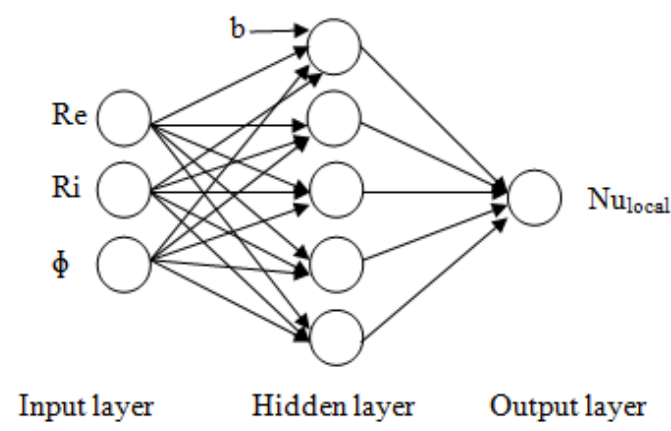

Fig.3: Schematic representation of a multilayer feed forward network consisting of three inputs, one hidden layer with five neurons and one output. 


\subsection{Training ANN}

The back-propagation method is the most popular training algorithm. The input and output data are trained in ANN so that the weights can be adjusted to give the same outputs as found in the training data. The inputs (v) into a neuron are multiplied by their corresponding connection a weight $(\mathrm{W})$, summed together and bias is added to the sum. This sum is transformed through a transfer function $(f)$ to produce the required output, which may be passed to other neurons. After propagating an input through the network, the error is calculated and the error is propagated back through the network while the weights are adjusted in order to make the error smaller. The number of iterations of predicting the output is selected as 500 for the present network. The training data have been selected $70 \%$ of the total data and the remaining data are selected for testing. Neural network requires that the range of the both input and output values should between 0.1 and 0.9 due to the restriction of the sigmoid function. Therefore, the numerical data evaluated in this study are normalized by the following equation:

$$
v_{n}=\left(\frac{v_{i}-v_{\min }}{v_{\max }-v_{\min }}\right)
$$

Where $v_{n}=$ normalized value, $v_{i}=$ actual input (or output) value, $v_{\max }=$ Maximum value of the inputs (or outputs), $\mathrm{v}_{\min }=$ Minimum value of the inputs (or outputs)

\section{Gene Expression Programming (GEP)}

GEP is an algorithm of developing functions through population based evolutionary technique combining the advantages of Genetic Algorithm (GA) and Genetic Programming (GP), proposed by Ferreira(Ferreira, 2001). It is an extension of GA in which simple or linear chromosomes are encoded to the individuals, after that transformed into an expression parse tree completely separating the genotype and phenotype which makes GEP much faster (100 - 10,000 times) than the GP (Ferreira, 2001, Ferreira, 2002). For example, an expression tree of an algebraic expression (Eq. 14) is represented in Fig. 4.

$$
(o+q) *(r-s)
$$

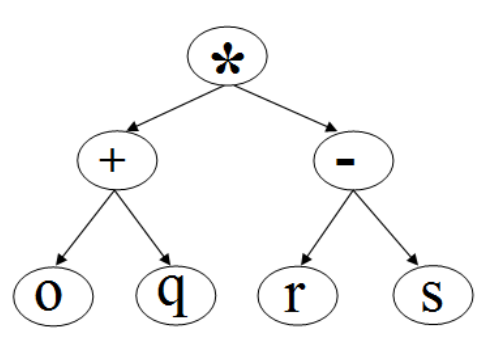

Fig.4: Expression tree of Eq. 14.

In GEP, there are multiple genes in a chromosome and several subprograms are encoded with each gene. Therefore, any program can be encoded for efficient evolution the solutions by the novel structures of the genes in the GEP algorithm (Ferreira, 2001). The entire feasible region of the problem is used by the novel structure of the genes in the GEP to have efficient genetic operators looking for the solutions. In GEP, more complex scientific and technological programs can be solved with the help of linear chromosomes and Expression Trees (ET). Each linear chromosome is manipulated genetically, i.e. replication, mutation, recombination and transposition (Ferreira, 2001). They are composed of genes structurally comprised of the head and tail part. The tail length $\left(\mathrm{t}_{\mathrm{l}}\right)$ is a function of head length $\left(\mathrm{h}_{1}\right)$ and number of arguments of the function $(\mathrm{m})$ and expressed as the following equation:

$$
t_{l}=h_{l}(m-1)+1
$$

The flow chart of GEP is presented in the Fig. 5 (Ferreira, 2001). 


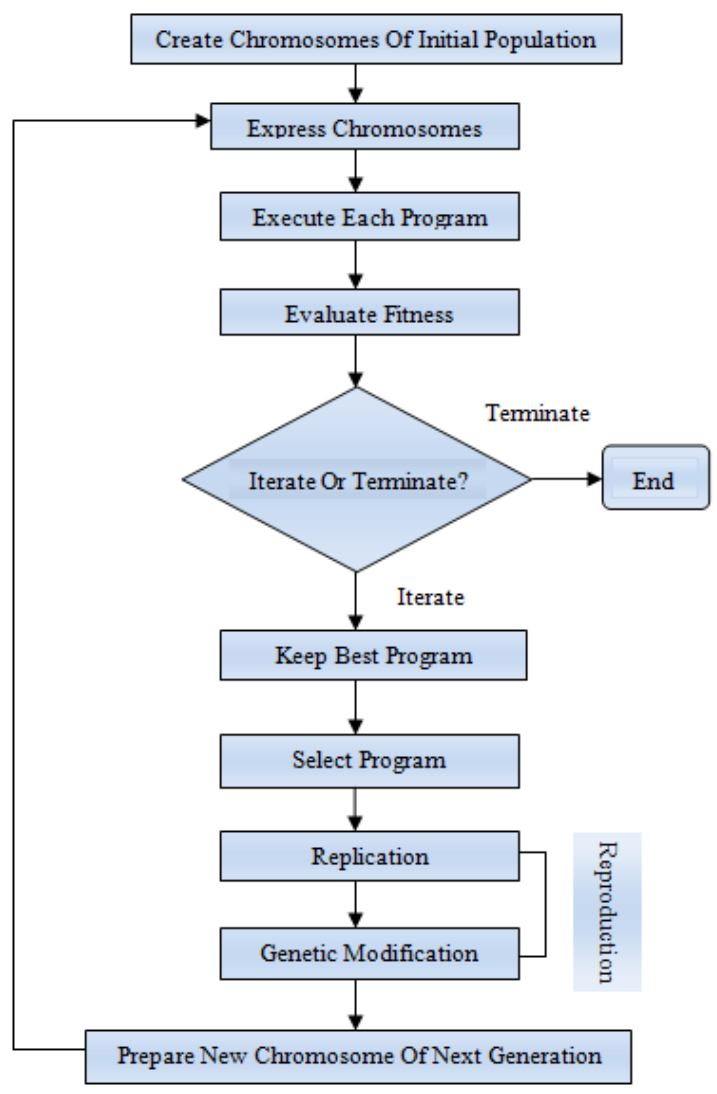

Fig. 5: Flowchart of GEP.

\subsection{GEP model of present input and output}

The relation between input and output data can be expressed by GEP. In the present study, the training and testing data for the proposed GEP are Re, $\mathrm{Ri}$ and $\phi$ as input and $\mathrm{Nu}_{\text {local }}$ as output. As same as the ANN model, $70 \%$ data have been selected for training and remaining $30 \%$ data for testing. The data are evaluated on the GeneXproTools (GeneXproTools, 2014) to develop the empirical models of input and output data.

Different symbols from Function set and Terminal set are used in mathematical expressions. Various arithmetic operators and mathematical functions available in function set are used in this study (encapsulated in Table. 3) to generate the relation between input and output by evolving the model.

Table.3: Different Parameters of GEP Model

\begin{tabular}{|c|c|}
\hline Parameter & Values \\
\hline Function Set & $\begin{array}{c}+,-,, /, \text { Sqrt, Pow, log, Exp, NOT }(1-\mathrm{x}), \mathrm{x}^{2}, \mathrm{x}^{3}, \text { Cube } \\
\operatorname{root}(\sqrt[3]{x})\end{array}$ \\
\hline Chromosomes & 30,40 \\
\hline Head Size & $5,8,10$ \\
\hline Number Of Genes & 5 \\
\hline Linking Function & Addition \\
\hline Mutation Rate & 0.044 \\
\hline Inverse rate & 0.1 \\
\hline One-point recombination rate & 0.3 \\
\hline Two-point recombination rate & 0.3 \\
\hline Gene recombination rate & 0.1 \\
\hline Gene transportation rate & 0.1 \\
\hline
\end{tabular}


The numbers of programs in the each linear chromosome are set by the population size i.e. number of chromosomes. The more population size makes the iteration time longer. The program is considered as converged when there are no considerable changes in the performance of the model.

In the present study, the main goal of utilization of GEP is to obtain the explicit expression of $\mathrm{Nu}_{\mathrm{avg}}$ relating with $\mathrm{Re}, \mathrm{Ri}$ and $\phi$. The ET of the explicit formula of $\mathrm{Nu}_{\mathrm{avg}}$ is depicted in Figs. 6-8 and the formula based on the ET is expressed in the Eq. 16 where $\mathrm{d}(0), \mathrm{d}(1)$ and $\mathrm{d}(2)$ be the volume fraction $(\phi)$, Reynolds number $(\mathrm{Re})$ and Richardson number $(\mathrm{Ri})$ respectively.

$$
\begin{aligned}
& \mathrm{Nu}_{\mathrm{avg}}=\sqrt{\left(\left(2.45+\left(\mathrm{Re}+\left((\mathrm{Ri}+\mathrm{Re})-\left(\Phi^{*} 13.07\right)\right)\right)\right)\right.}+(((-4.63-(-4.38-\Phi)) /((-1.26-\mathrm{Ri})-\mathrm{Ri}))+\Phi) \\
& +(((\sqrt[3]{\Phi}+\mathrm{Re})-(1.48+0.46))-(\operatorname{Re}-(6.48+0.46)))+\left(-7.93+\mathrm{e}^{(((1.0+4.60)-(\mathrm{Re} / 9.52))+(\Phi * \mathrm{Ri}))}\right) \\
& +((\Phi * \sqrt{8.83} * \sqrt[3]{(22.32-\operatorname{Re}) *(-8.77)}))
\end{aligned}
$$
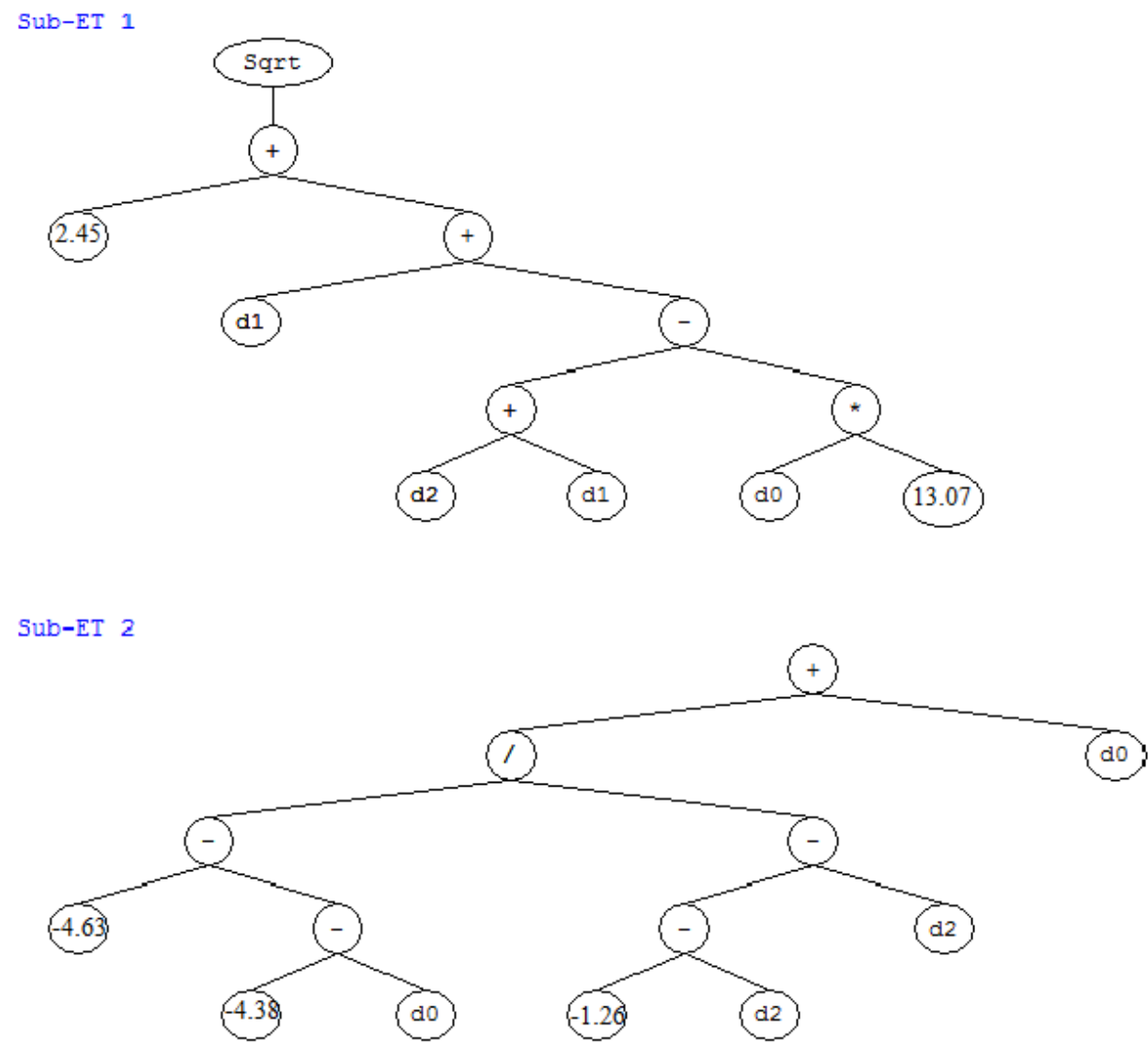

Fig.6: Sub Expression Tree of genes 1-2 for $\mathrm{Nu}_{\mathrm{avg}}$.

\section{Results and Discussions}

\subsection{Validation of Present Results}

The present numerical data are validated with the available published data. The present data are validated with circular cylinder at $\mathrm{Re}=100$ with both adding and opposing buoyancy forces. Numbers of trials have been performed to find quite accurate value and the time step is chosen for every case as 0.01 . The parameter used for 
validation is $\mathrm{Nu}_{\text {avg. }}$. The present numerical values are in very good agreement with the published results, tabulated in Table 4.
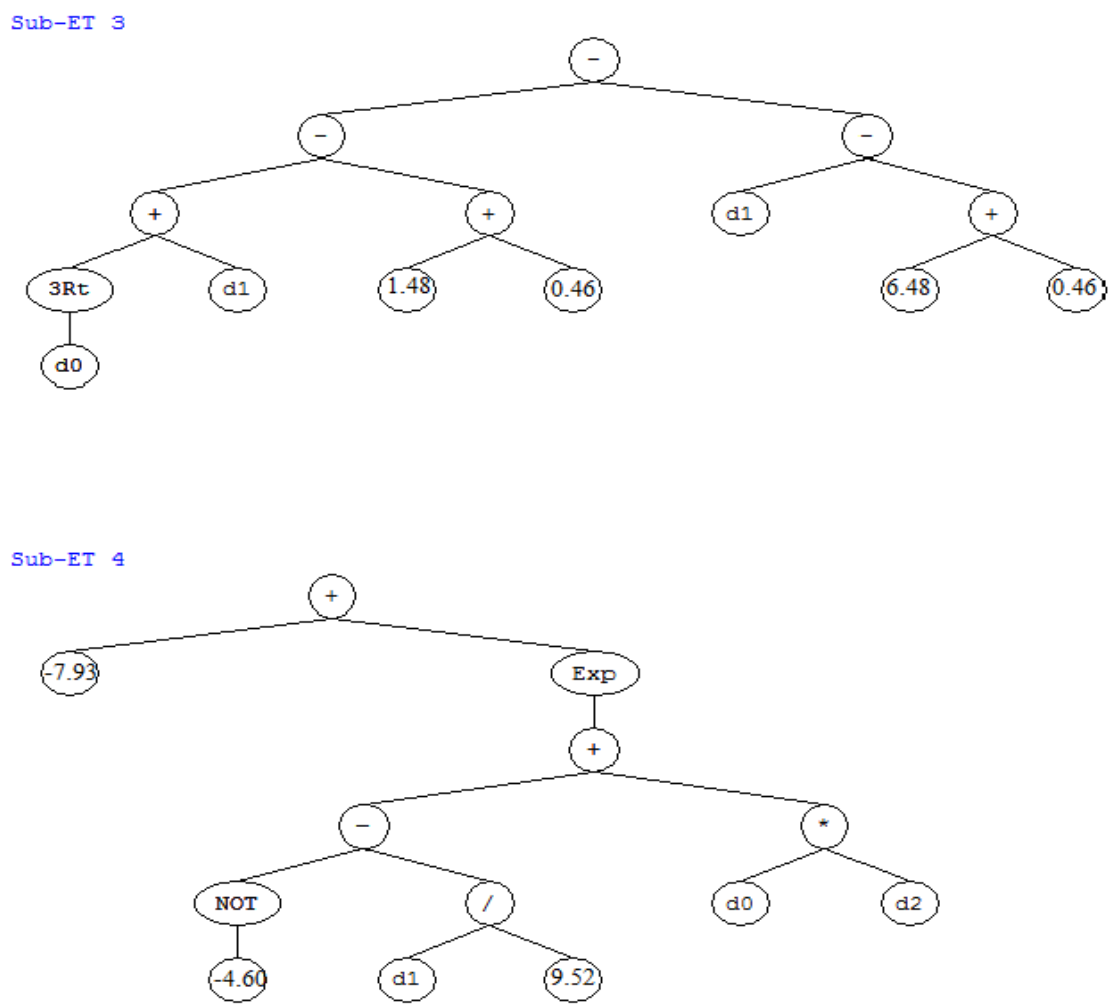

Fig.7: Sub Expression Tree of genes 3-4 for $\mathrm{Nu}_{\text {avg }}$.

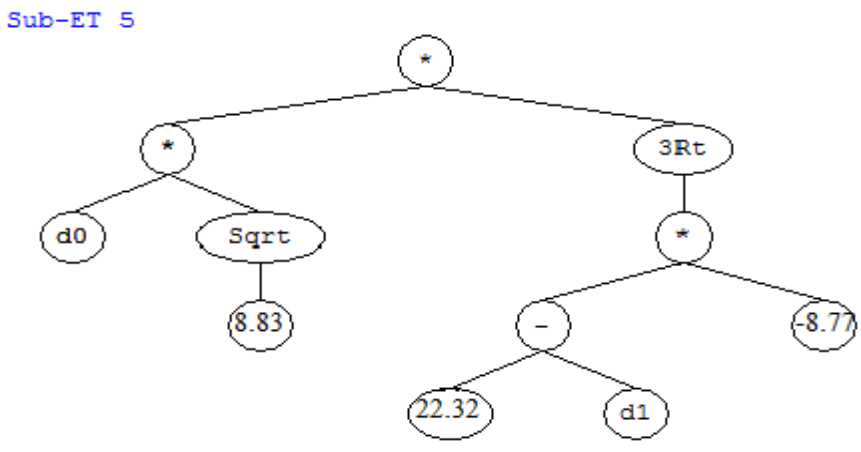

Fig. 8: Sub expression Tree of gene 5 for $\mathrm{Nu}_{\text {avg. }}$.

Table 4: Validation of present numerical results with other literature

\begin{tabular}{|c|c|c|c|c|}
\hline $\mathrm{Re}$ & $\mathrm{Ri}$ & $\begin{array}{c}\text { Volume } \\
\text { fraction }(\%)\end{array}$ & Study & $\mathrm{Nu}_{\mathrm{avg}}$ \\
\hline \multirow{4}{*}{100} & \multirow[t]{2}{*}{1} & \multirow{4}{*}{0} & Present & 11.52009 \\
\hline & & & Sarkar et. al (2012) & 11.52155 \\
\hline & \multirow[t]{2}{*}{-1} & & Present & 11.15485 \\
\hline & & & Sarkar et. al (2012) & 11.1629 \\
\hline
\end{tabular}




\subsection{Heat transfer prediction}

The heat transfer characteristic over the circular cylinder due to the presence of nanofluid is presented by means of local and average Nusselt number. The present numerical outputs are in very good agreement with Sarkar et al., (2012). It is found that by increasing of Reynolds number and solid volume fraction, heat transfer rate is increased for both the condition of adding and opposing of buoyancy. As the Reynolds number is increased, more clustering of the isotherms is seen at the front surface of the cylinder, due to which the heat transfer rate is enhanced. Even also, by increasing the solid volume fraction, the volume of nano particles striking the cylinder is increased, which causes more heat transfer from cylinder surface, by means of which the heat transfer rate is also increased. The training and testing data are collected from numerical analysis for $\mathrm{Re}=80$ to $180, \phi=0$ to $15 \%$ and $\mathrm{Ri}=1$ and -1 . The training data are separated from the total data by keeping the particular testing data alongside. For training the network, different combinations of Reynolds number and solid volume fraction are selected for $\mathrm{Ri}=1$ and -1 . For training the present ANN model and GEP model, Reynolds number, Ri and volume fraction have taken as input and local Nusselt number is found as output. The average Nusselt number $\left(\mathrm{Nu}_{\mathrm{avg}}\right)$ has been calculated by time averaging the local Nusselt number over the cylinder surfaces.

The variation of local Nusselt number about the cylinder surface is shown in Fig.6 for $\mathrm{Re}=100, \phi=0.05$ and $\mathrm{Ri}=1$. Also the instantaneous vorticity and isotherm is displayed in Fig.9. Only one case is of predicting the local Nusselt number is depicted and it shows that a very good agreement between the numerical data and the predicted data (refer Fig. 10). Fig 11 and 12 (a) shows the variation of numerical and predicted data after testing the model, which are clearly depicted that the predicted data are in good agreement with the numerical data for every Reynolds number and volume fraction.

The error between the numerical values and the ANN and GEP predicted values are presented as Adj. $\mathrm{R}^{2}$ (It is defined as the error measuring value which is used to measure the quantity of the discrepancy in the dependent variable accounted for by the explanatory variables in a multiple linear regression.) and mean relative error (MRE) which is expressed as given below and the comparison between them is tabulated in Table 5:

$$
\begin{aligned}
& \operatorname{Adj.} R^{2}=1-\frac{\sum_{i}\left(N_{i}-P_{i}\right)^{2} / n_{s}-t_{r}-1}{\sum_{i}\left(N_{i}-\bar{N}\right)^{2} / n_{s}-1} \\
& M R E=\frac{1}{n_{s}} \sum_{i=1}^{n_{s}} \frac{\left|N_{i}-P_{i}\right|}{N_{i}} \times 100
\end{aligned}
$$

Where, $\mathrm{n}_{\mathrm{s}}=$ Sample Size,

$\mathrm{t}_{\mathrm{r}}=$ total number of regressors in the training model.

$\mathrm{N}_{\mathrm{i}}=$ Actual Value.

$\mathrm{P}_{\mathrm{i}}=$ Predicted Value and

$$
\bar{N}=\frac{1}{n_{s}} \sum_{i=1}^{n_{s}} N_{i}
$$
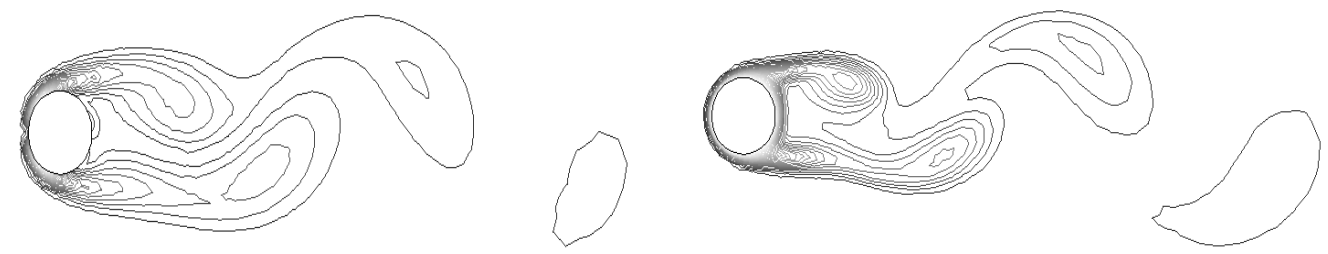

Fig.9: Instantaneous Vorticity (left) and Isotherm (right) at $\mathrm{Re}=100, \mathrm{Ri}=1$ and $\phi=0.05$. 


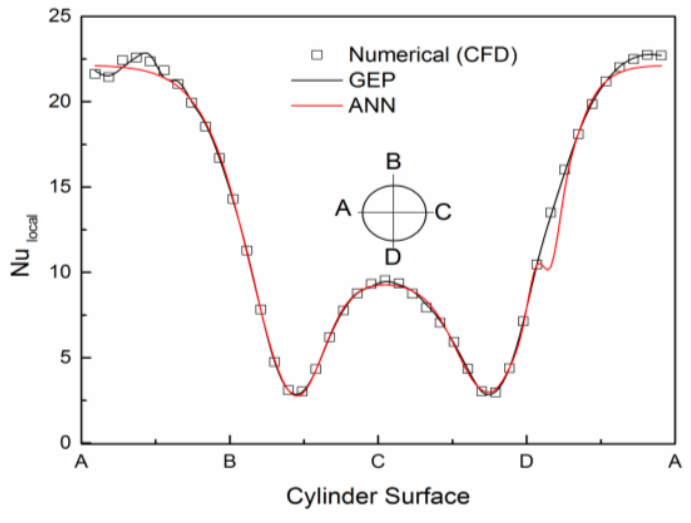

(a)

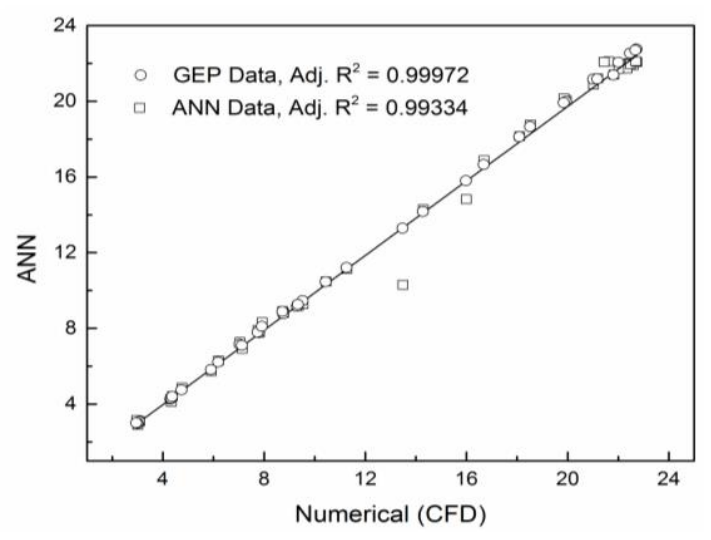

(b)

Fig.10: (a) Comparison of $\mathrm{Nu}_{\text {local }}$ of Numerical and predicted data and (b) Fitting line plot of predicted data at $\mathrm{Re}=100, \mathrm{Ri}=1$ and $\phi=0.05$.

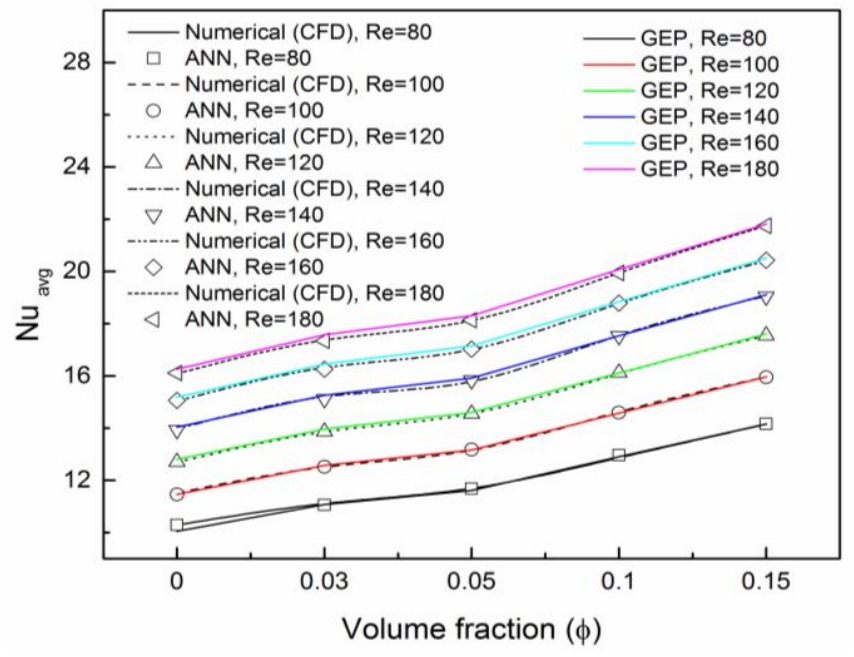

(a)

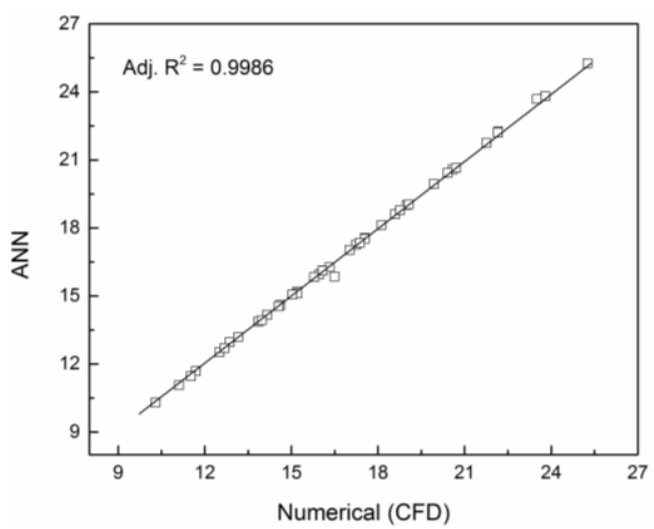

(b)

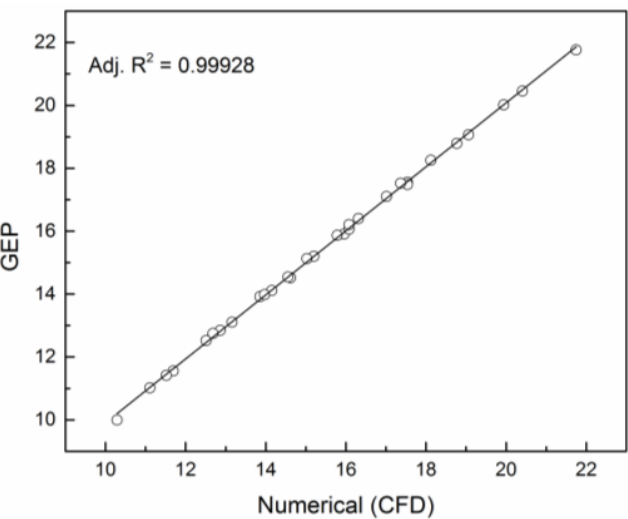

(c)

Fig.11: (a) Comparison of $\mathrm{Nu}_{\text {avg }}$ of Numerical and predicted data (b) Fitting line plot of predicted data by ANN and (c) Fitting line plot of predicted data by GEP at $\mathrm{Ri}=1$. 


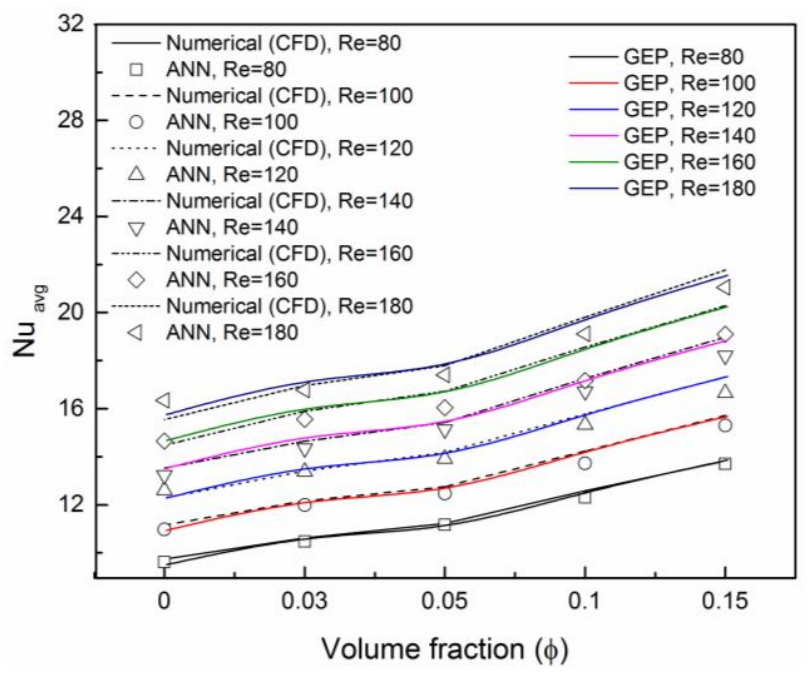

(a)

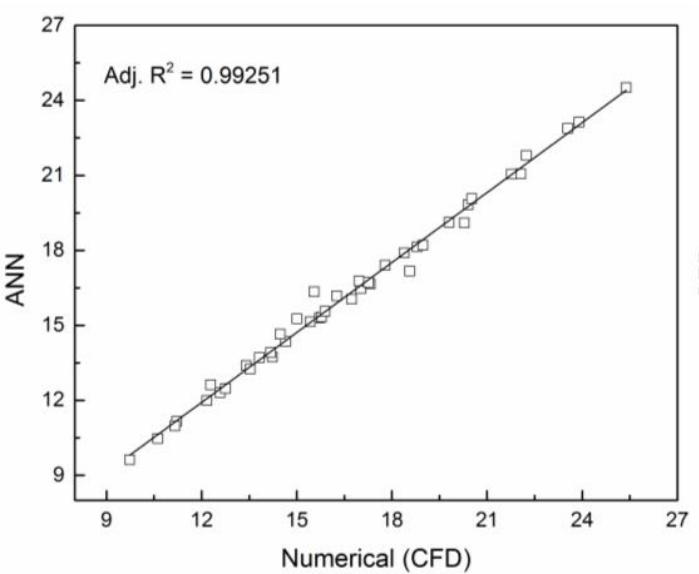

(b)

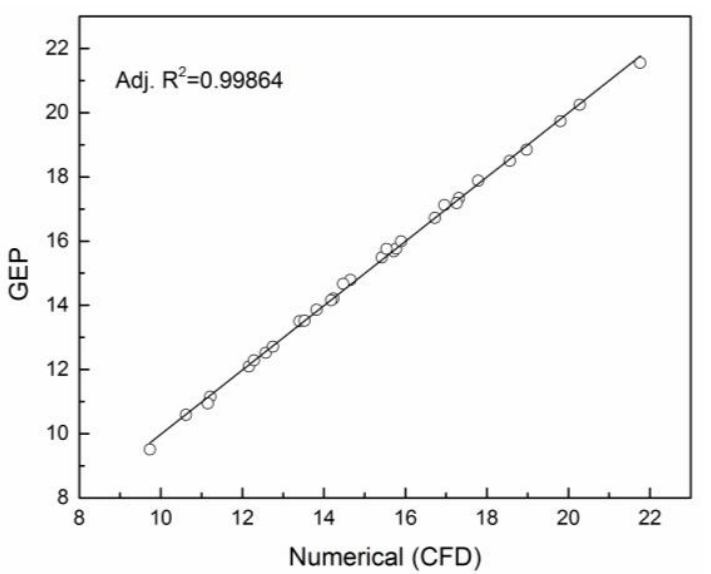

(c)

Fig.12: (a) Comparison of $\mathrm{Nu}_{\text {avg }}$ of Numerical and predicted data (b) Fitting line plot of predicted data by ANN and (c) Fitting line plot of predicted data by GEP at $\mathrm{Ri}=-1$.

It is found that the mean relative error of $\mathrm{ANN}$ predicted data of average Nusselt number with $\mathrm{Ri}=1$ and -1 are $2.645 \%$, and $2.638 \%$, respectively, whereas for GEP, the errors are $0.49 \%$ and $0.578 \%$, respectively (refer Table. 5). It is obvious for prediction models that, more values in training, more accurate will be the prediction.

Table 5: A comparison of GEP and ANN

\begin{tabular}{|c|c|c|c|c|c|}
\hline Value & $\mathrm{Ri}$ & Model & Adj. $\mathrm{R}^{2}$ & MRE & Adj. $\mathrm{R}_{\mathrm{GEP}}^{2} /$ Adj. $\mathrm{R}_{\text {ANN }}^{2}$ \\
\hline \multirow{4}{*}{$\mathrm{Nu}_{\mathrm{avg}}$} & \multirow[t]{2}{*}{1} & GEP & 0.99928 & 0.49 & \multirow[t]{2}{*}{1.001} \\
\hline & & ANN & 0.9986 & 2.645 & \\
\hline & \multirow[t]{2}{*}{-1} & GEP & 0.99864 & 0.578 & \multirow[t]{2}{*}{1.01} \\
\hline & & ANN & 0.99251 & 2.638 & \\
\hline
\end{tabular}




\section{Conclusion}

Back propagation Artificial Neural Network and GEP are used to predict the mixed convection heat transfer characteristics of water based nanofluid flowing over a circular cylinder at low Reynolds number with adding and opposing of buoyancy force. For this purpose, series of numerical data have been developed for the cylinder model with a validation which shows a very good agreement of present result with the previously available published data. For training and testing the network, several numerical cases with combinations of input variables are created and output data are generated. The validations of the applied predicted methods were checked in several cases to ensure the effectiveness to establish the results with less permissible error. It is found that the Finite Volume method based numerical procedure can calculate efficiently the behavior of mixed convection over a circular cylinder. It is found that the Average Nusselt number is directly proportional to the nanofluid volume fraction and Reynolds numbers for both adding and opposing buoyancy cases. It can also be concluded by analyzing the results that the back propagation artificial neural network and GEP both can predict the local and average Nusselt number accurately with a minimum mean relative error where GEP is a more efficient algorithm for prediction than ANN; hence reducing the computational time in the CFD calculation while achieving acceptable accuracy. Therefore, in different analysis of heat transfer where experimental and simulation requires more time and also more expensive; GEP can be utilized to predict the heat transfer characteristics.

\section{References:}

Abu-nada, E. and Oztop, H. F. (2009): Effects Of Inclination Angle On Natural Convection In Enclosures Filled With $\mathrm{Cu}$-Water Nanofluid, International Journal of Heat and Fluid Flow, 30, 669-678. http://dx.doi.org/10.1016/j.ijheatfluidflow.2009.02.001

Buongiorno, J. (2006): Convective Transport In Nanofluids, Journal of Heat Transfer, 128, $240-250$. http://dx.doi.org/10.1115/1.2150834

Chakraborty, J., Verma, N. and Chhabra, R. (2004): Wall Effects In Flow Past A Circular Cylinder In A Plane Channel: A Numerical Study, Chemical Engineering and Processing: Process Intensification, 43, 1529-1537. http://dx.doi.org/10.1016/j.cep.2004.02.004

Chen, C.-L., Chang, S.-C. and Chang, C.-K. (2014): Lattice Boltzmann Simulation For Mixed Convection Of Nanofluids In A Square Enclosure, Applied Mathematical Modelling, 39, 2436-2451.

Chhabra, R., Soares, A. and Ferreira, J. (2004): Steady Non-Newtonian Flow Past A Circular Cylinder: A Numerical Study, Acta Mechanica, 172, 1-16. http://dx.doi.org/10.1007/s00707-004-0154-6

Daungthongsuk, W. and Wongwises, S. (2007): A Critical Review Of Convective Heat Transfer Of Nanofluids, Renewable and Sustainable Energy Reviews, 11, 797-817. http://dx.doi.org/10.1016/j.rser.2005.06.005

Dey, P. and Das, A. K. (2014): Numerical Analysis Of Characteristic Of Flow And Heat Transfer Due To Natural Convection In A Enclosure (Square) Using Nano-Fluid, Advances in Energy Conversion Technologies (ICAECT), International Conference on, (2014): IEEE, 92-98.

Eastman, J., Choi, S., Li, S., Yu, W. and Thompson, L. (2001): Anomalously Increased Effective Thermal Conductivities Of Ethylene Glycol-Based Nanofluids Containing Copper Nanoparticles, Applied Physics Letters, 78, 718-720. http://dx.doi.org/10.1063/1.1341218

Ferreira, C. (2001): Gene Expression Programming: A New Adaptive Algorithm For Solving Problems, Complex Syst, 13, 87-129.

Ferreira, C. (2002): Gene Expression Programming In Problem Solving, Soft Computing and Industry. Springer. FLUENT, I. (2006): FLUENT 6.3 user's guide. Fluent documentation.

Garoosi, F., Rohani, B. and Rashidi, M. M. (2015): Two-Phase Mixture Modeling Of Mixed Convection Of Nanofluids In A Square Cavity With Internal And External Heating, Powder Technology, 275, $304-321$. http://dx.doi.org/10.1016/j.powtec.2015.02.015

GENEXPROTOOLS (2014): Version: 5. GEPSOFT.

Golani, R. and Dhiman, A. (2004): Fluid Flow And Heat Transfer Across A Circular Cylinder In The Unsteady Flow Regime, The International Journal of Engineering And Science, Vol. 3, pp. 8-19.

Kakaç, S. and Pramuanjaroenkij, A. (2009): Review Of Convective Heat Transfer Enhancement With Nanofluids, International Journal of Heat and Mass Transfer, 52, 3187-3196. http://dx.doi.org/10.1016/j.ijheatmasstransfer.2009.02.006 
Khanafer, K., Vafai, K. and Lightstone, M. (2003): Buoyancy-driven Heat Transfer Enhancement in a TwoDimensional Enclosure Utilizing Nanofluids, International Journal of Heat and Mass Transfer, 46, 3639-3653. http://dx.doi.org/10.1016/S0017-9310(03)00156-X

Kurtulus, D. F. (2009): Ability to Forecast Unsteady Aerodynamic Forces of Flapping Airfoils by Artificial Neural Network, Neural Computing and Applications, 18, 359-368. http://dx.doi.org/10.1007/s00521-008-0186$\underline{2}$

Mahír, N. and Altaç, Z. (2008): Numerical Investigation of Convective Heat Transfer In Unsteady Flow Past Two Cylinders in Tandem Arrangements, International Journal of Heat and Fluid Flow, 29, 1309-1318. http://dx.doi.org/10.1016/j.ijheatfluidflow.2008.05.001

Martí, P., Shiri, J., Duran-ros, M., Arbat, G., De cartagena, F. R. and Puig-bargués, J. (2013): Artificial Neural Networks vs. Gene Expression Programming for Estimating Outlet Dissolved Oxygen in Micro-Irrigation Sand Filters Fed With Effluents, Computers and Electronics in Agriculture, 99, 176-185. http://dx.doi.org/10.1016/j.compag.2013.08.016

Park, J., Kwon, K. and Choi, H. (1998): Numerical Solutions of Flow Past a Circular Cylinder at Reynolds Numbers up to 160, KSME International Journal, 12, 1200-1205.

Posdziech, O. and Grundmann, R. (2007): A Systematic Approach to the Numerical Calculation of Fundamental Quantities of the Two-Dimensional Flow Over a Circular Cylinder, Journal of Fluids and Structures, 23, 479499. http://dx.doi.org/10.1016/j.jfluidstructs.2006.09.004

Rahman, M., Alim, M., Saha, S. and Chowdhury, M. (2009): Mixed Convection in a Vented Square Cavity with a Heat Conducting Horizontal Solid Circular Cylinder, Journal of Naval Architecture and Marine Engineering, 5, 37-46. http://dx.doi.org/10.3329/jname.v5i2.2504

Rahman, M. M., Karim, M. M. and Alim, M. A. (2007): Numerical Investigation of Unsteady Flow Past a Circular Cylinder Using 2-D Finite Volume Method, Journal of Naval Architecture and Marine Engineering, 4, 27-42.

Santra, A. K., Chakraborty, N. and SEN, S. (2009): Prediction of Heat Transfer due to Presence of Copperwater Nanofluid Using Resilient-Propagation Neural Network, International Journal of Thermal Sciences, 48, 1311-1,318. http://dx.doi.org/10.1016/j.ijthermalsci.2008.11.009

Sarkar, S., Dalal, A. and Biswas, G. (2011): Unsteady Wake Dynamics and Heat Transfer in Forced and Mixed Convection Past a Circular Cylinder in Cross Flow for High Prandtl Numbers, International Journal of Heat and Mass Transfer, 54, 3536-3551. http://dx.doi.org/10.1016/j.ijheatmasstransfer.2011.03.032

Sarkar, S., Ganguly, S. and Biswas, G. (2012): Mixed Convective Heat Transfer of Nanofluids Past A Circular Cylinder in Cross Flow in Unsteady Regime, International Journal of Heat and Mass Transfer, 55, 4783-4799. http://dx.doi.org/10.1016/j.ijheatmasstransfer.2012.04.046

Selimefendigil, F. and Öztop, H. F. (2015): Numerical Investigation and Reduced Order Model of Mixed Convection at a Backward Facing Step with a Rotating Cylinder Subjected to Nanofluid, Computers and Fluids, 109, 27-37. http://dx.doi.org/10.1016/j.compfluid.2014.12.007

Shi, J.-M., Gerlach, D., Breuer, M., Biswas, G. and Durst, F. (2004): Heating Effect On Steady And Unsteady Horizontal Laminar Flow Of Air Past A Circular Cylinder, Physics of Fluids (1994-present), 16, 4331-4345.

Sreekanth, S., ramaswamy, H., Sablani, S. and Prasher, S. (1999): A Neural Network Approach For Evaluation Of Surface Heat Transfer Coefficient, Journal of Food Processing And Preservation, 23, 329-348. http://dx.doi.org/10.1111/j.1745-4549.1999.tb00389.x

Tiwari, R. K. and Das, M. K. (2007): Heat Transfer Augmentation In A Two-Sided Lid-Driven Differentially Heated Square Cavity Utilizing Nanofluids, International Journal of Heat and Mass Transfer, 50, 2002-2018. http://dx.doi.org/10.1016/j.ijheatmasstransfer.2006.09.034

Trisaksri, V. and Wongwises, S. (2007): Critical Review Of Heat Transfer Characteristics Of Nanofluids, Renewable and Sustainable Energy Reviews, 11, 512-523. http://dx.doi.org/10.1016/j.rser.2005.01.010

Tritton, D. J. (1959): Experiments on the Flow Past A Circular Cylinder At Low Reynolds Numbers, Journal of Fluid Mechanics, 6, 547-567. http://dx.doi.org/10.1017/S0022112059000829

Xuan, Y. and Li, Q. (2000): Heat Transfer Enhancement Of Nanofluids, International Journal of Heat and Fluid Flow, 21, 58-64. http://dx.doi.org/10.1016/S0142-727X(99)00067-3

Yacob, N. A., Ishak, A., Pop, I. and Vajravelu, K. (2011): Boundary Layer Flow Past A Stretching/Shrinking Surface Beneath An External Uniform Shear Flow With A Convective Surface Boundary Condition In A Nanofluid, Nanoscale Research Letters, 6, 1-7. http://dx.doi.org/10.1186/1556-276X-6-314 